\title{
The Prevention and Reduction of the Bullwhip Effect by Electronic Data Interchange and Collaborative Forecasting
}

\author{
Bahija Jardini, Assistant Professor
}

Hassania School of Public Works, Morocco

Doi:10.19044/esj.2021.v17n23p163

Submitted: 26 April 2021

Accepted: 01 July 2021

Published: 31 July 2021
Copyright 2021 Author(s)

Under Creative Commons BY-NC-ND

4.0 OPEN ACCESS

Cite As:

Jardini B. (2021). The Prevention and Reduction of the Bullwhip Effect by Electronic Data Interchange and Collaborative Forecasting. European Scientific Journal, ESJ, 17(23), 163. https://doi.org/10.19044/esj.2021.v17n23p163

\begin{abstract}
The bullwhip effect is a phenomenon of curious amplification of variations in demand as one moves away from the final customer. Popularized by Lee and al., (1997), the bullwhip effect has negative consequences on all actors in the supply chain because it generates considerable loss of profits: Too much stock, loss of sales, poor customer service, insufficient quality and multiple disruptions of flow and organization. To prevent and reduce the bullwhip effect, various tools are recommended. The Electronic Data Interchange (EDI) is among the most important given its impact on accelerating information sharing throughout the supply chain. This paper aims to shed light on the role of EDI, VMI (Vendor-managed inventory) and CPFR (collaborative planning forecasting and replenishment) in the prevention and reduction of the bullwhip effect in the supply chain.
\end{abstract}

Keywords: Bullwhip effect, automotive supply chain

\section{Introduction}

A relatively recent phenomenon, the Bullwhip Effect has been widely described and explained in the literature. Lee et al., (1997) shows the existence of increasing variability in demand by moving away from the final customer despite rational behavior of supply chain actors. It is represented by an abnormal amplification of changes in demand as one moves away from the end buyer. Popularized by Lee et al., (1997), the bullwhip effect has negative consequences on all actors in the chain because it generates considerable loss 
of profits: Too much stock, loss of sales, poor customer service, poor quality insufficient and multiple disruptions of flow and organization; they explain this phenomenon by four main causes: updated demand forecasts, subdivision policies, anticipation of shortages and price variations.

Chatfield et al. (2004) attempt to quantify the impact of the variability of replenishment times and the quality of the information shared on the boost effect in the case of standardized production. Their conclusion is that information sharing can dramatically reduce the boost effect and that variability in lead times tends to increase it. Sucky (2009) is interested in the structure of the supply chain as an aggravating or mitigating element of the boost effect. Cheng (2009) analyzes the impact of the combination of replenishment policies on the performance of the Supply Chain dedicated to standardized production and on the Bullwhip Effect. The non-existence of shared information or the sharing of unnecessary information are shown as causes of the Bullwhip Effect by articles with the purpose of both information sharing and the Bullwhip effect.

In addition, the efficient exchange of information between the partners of a supply chain can prevent and avoid a bullwhip effect, in addition, it can contribute to an increased performance of the supply chain. In fact, in "a world which reduces international space to the list of a telephone directory" (Ettighoffer, 1992), in addition to an electronic mail book and internet contacts, we are witnessing a strong rise in exchanges. of inter-company data, replacing or supplementing intra-company networks. Manufacturers have understood that it is essential to synchronize the tense flow of materials with the flow of information through EDI technology (Electronic Data Interchange) which is a tool that provides very remarkable benefits in terms of flow management. information between supply chain partners and therefore on the quality of information. EDI is a technology which therefore fits into a context of globalization and Total Quality (Raymond, Blili and Bergeron, 1994).

The aim of our article is to shed light on the role of EDI in preventing and reducing the bullwhip effect. First, we will try to conceptualize the basics: the Bullwhip effect, Electronic Data Interchange. Secondly, taking inspiration from the literature, we discuss how VMI (vendor managed inventory) and CPFR (collaborative planning forecasting and replenishment) ensure the prevention of the Bullwhip effect by better sharing of information in time real. Thirdly, we deal with the impact of EDI on information flows and therefore on the prevention of the Bullwhip effect before concluding with an analysis of semi-structured interviews with players in the automotive supply chain who explained how they deal with this kind of phenomenon and to shed some light on the question: whether widespread EDI helps to mitigate, prevent and counteract this boost effect. 


\section{Origin of the concept Bullwhip effect}

The bullwhip effect is a phenomenon that consists of an extraordinary amplification of variations in demand as one moves away from the end customer. The name was popularized by Lee et al. (1997), but the first to study it is Jay Forrester who sees its origin in the irrationality of the behavior of actors in the logistics chain. In 1961, Forrester, through the Massachusetts Institute of Technology (MIT), published his book "Industrial Dynamics" where he first introduced the term "bullwhip effect". Since the end of the 1980s, other authors interested in the Bullwhip effect have explained that the cause lies rather in the interactions that exist between these same actors whose behavior is considered rational and locally optimized. Several factors can be responsible for this effect:

- The degree of imprecision of the information,

- The lack of transparency in the logistics chain,

- Long Lead-Times,

- A pronounced disconnection between consumption (actual customer demand) and production (actual factory activity).

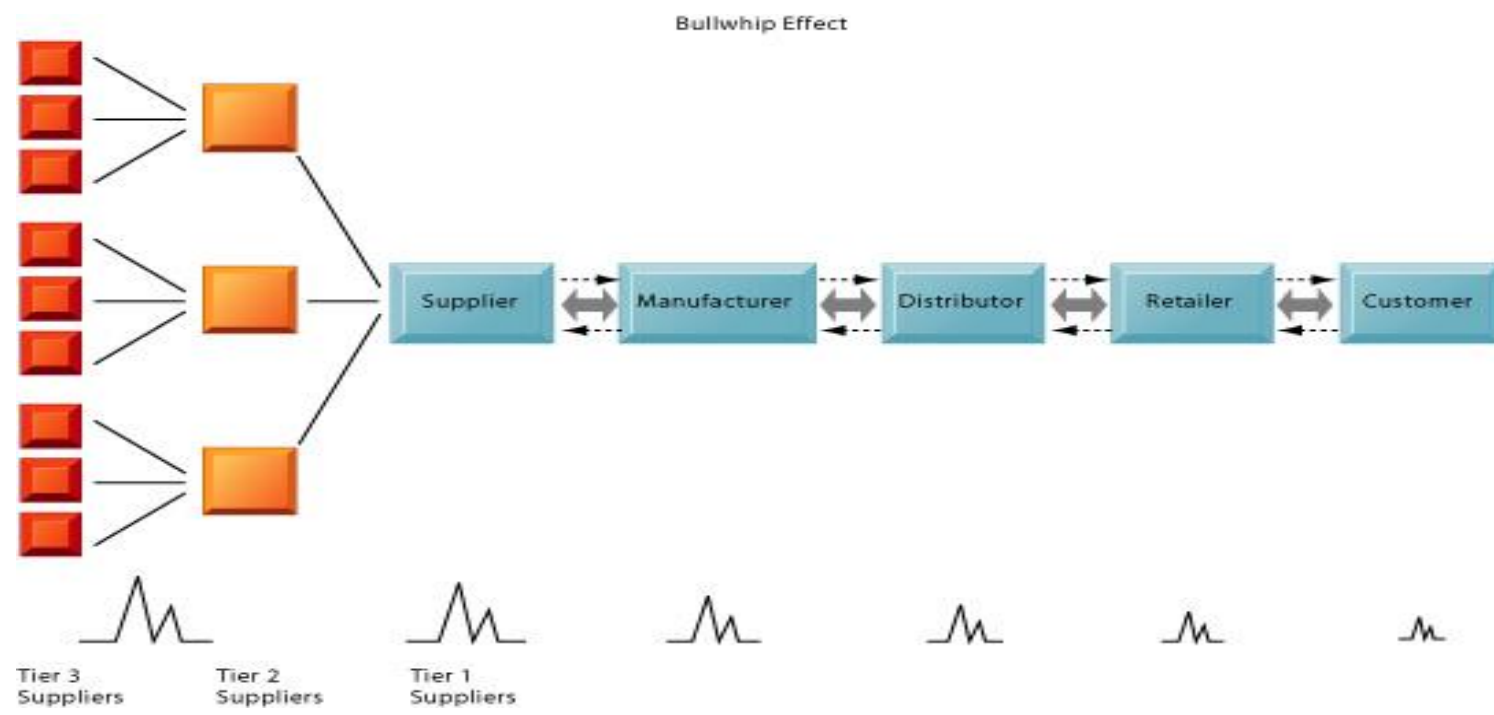

Figure 1: Amplification of stocks demand and variations in supply chain

\section{Main causes of the bullwhip effect}

Lee and al. (1997) identify the main causes that are at the origin of the boost effect in the downstream logistics chain, they are four in number:

- Updating the demand forecast,

- The size of the lots,

- Anticipation of shortages,

- Price variability. 
The articles that followed and which focused on the causes of the boost effect generally focused on one of the causes of this phenomenon in order to understand the impact and measure its relative importance in relation to other. In a downstream logistics chain organized in series, Chatfield et al. (2004) attempt to quantify the impact of the variability of replenishment times and the quality of the information shared on the boost effect in the case of standardized production. Their conclusion is that information sharing can dramatically reduce the boost effect and that variability in lead times tends to increase it. Sucky (2009) is interested in the structure of the supply chain as an aggravating or mitigating factor of the boost effect. It demonstrates, through a simulation model, that the boost effect tends to be overestimated because it is generally measured on serial logistics chains which do not allow pooling and compensation phenomena to be taken into account. Cheng (2009) analyzes the impact of the combination of replenishment policies on the performance of the supply chain and on the Bullwhip effect in the downstream supply chain dedicated to standardized production. Wang et al. (2005), for their part, introduce the notion of the extended Bullwhip effect by adding socio-organizational causes to the list of its classic causes.

The non-existence of shared information or the sharing of unnecessary information are presented as causes of the Bullwhip effect by articles whose purpose is both information sharing and boosting effect. Only Childerhouse and al. (2008) discuss the mechanisms behind the boost effect in the upstream logistics chain. They use the results of a study carried out in the automotive industry to establish the cause and effect link, represented in the form of a vicious circle, between the instability of forecast production programs and the increasing oscillations phenomena generated. accordingly along the upstream logistics chain. This phenomenon is not the preserve of industries that experience strong fluctuations in demand, such as those with high seasonality. This is why, despite a reliable and stable final demand, some industries spend millions of euros in a permanent struggle between satisfaction of deliveries (painfully provided at great exceptional transport costs) and management of minimum stocks (which experience strong fluctuations and high management costs).

Generally, the various links in a logistics chain only have access to fragmented or incomplete information. Very often, this is unreliable information: forecast demand far from actual demand, deliveries from suppliers that do not correspond to orders, commercial information that is difficult to interpret in terms of consumption. The information is imprecise and worse still, it is distorted by successive links in the chain. In many cases, the lack of flexibility and flexibility of production systems does not allow efficient production (without loss of productivity) of demands that vary greatly in volume and variety. Very large and often poorly controlled stocks are then 
generated in order to be able to meet these demands (long lead-time). The slightest fluctuation in demand causes either the fear of a break in delivery or overstock and very often both. Therefore, corrupted orders are generated to the suppliers.

\section{Prevention and reduction of the Bullwhip effect by EDI and other similar tools}

\subsection{Origin and definition of Electronic Data Interchange}

Born in the United States during the 1960s (Roesch, 1991), Electronic Data Interchange (EDI) is defined as the transfer from computer to computer, from one application to another, of data structured according to preestablished messages. and standardized by means of telecommunication. This technique allows the automatic exchange of data coded according to a previously agreed language between applications and heterogeneous information systems. Exchanges take place using various telecommunications networks (Jin et al., 2000). Even though EDI is used for internal communication, its main applications are aimed at facilitating collaboration between organizations such as the company, its suppliers, customers, carriers, etc. (Vlachos, 2004). EDI offers an alternative to traditional means of communication regarding the transfer of documents such as purchase orders, invoices, shipping notices, etc. (Vijayasarathy and Tyler, 1997). This structured data can be processed by computer information systems without any human intervention being required. Thus, the data transmitted by the transmission system can be directly retrieved and interpreted by the reception system (Jin et al., 2000).

Although the use of EDI has many advantages (Lim and Palvia, 2001), the reasons for its adoption are diverse and seem to have an impact on its use.

Different typologies of reasons for adopting EDI can be found in the literature (Masson and Ferguson, 1991; Vijayasarathy and Tyler, 1997). Customer satisfaction seems to be the main reason for its adoption, in fact, a large customer often forces the adoption of EDI on their "small" partners (Vlachos, 2004). EDI is also believed to reduce costs by reducing paperwork, eliminating the cost of entering data, improving accuracy, making it possible to receive timely information, accelerate cash flow and reduce stocks (Vijayasarathy and Tyler, 1997). EDI plays a key role in the supply chain: it makes it possible to improve inventory management and the optimal organization of deliveries (Vijayasarathy and Tyler, 1997) by directing the company towards a practical fluid management oriented towards response to the real needs of the final consumer (Craighead et al., 2006).

EDI offers better inventory management and improves the value chain between supply chain actors, it allows better efficiency in transaction processing and improved coordination between information systems (Hill and 
Scudder, 2002). Additionally, buyers and suppliers see the benefits of EDI in reducing errors associated with manual, paper-based systems. Decreased errors are directly correlated with better product quality, cost reductions, improved cash flow and optimization of the order cycle (Masson and Ferguson, 1991).

\subsection{Importance of Information Sharing}

Companies operating in decentralized supply chains around the world have realized the beneficial nature of sharing market data. In fact, the savings generated by information sharing vary between 3.4\% (Cachon and Fischer, 2000) and $10 \%$ of the total supply chain costs (Hosoda et al., 2008). When information sharing is part of the perspective of implementing decision coordination mechanisms, the benefit is even greater (Wu and Katock, 2006). Most of the articles focusing on information sharing suggest improving the coordination of the supply chain. (Cachon and Fisher, 2000) recommend accelerating the flow of information (including EDI) to improve the performance of the distribution supply chain and reduce the bullwhip effect. (Chen et al., 2006) propose to contractualize the notion of risk between customer and supplier to improve the overall profit of partners. (Ganesh et al., 2007) establish decision rules regarding the level of information sharing to be established between wholesaler and retailer based on the substitutability of finished products. (Croson and Donohue, 2005) suggest the use of different replenishment policies depending on the position of the flow in a serial supply chain.

\subsection{The VMI and CPFR tools and their impact on the Bullwhip effect}

Innovative decision-sharing and coordination mechanisms have integrated decentralized supply chains and are gradually gaining ground. Among these tools, the most original are certainly the VMI (vendor managed inventory) and the CPFR (collaborative planning forecasting and replenishment). The VMI is an agreement under which the distributor entrusts his supplier with the responsibility of managing his stocks. It is a process particularly used in mass distribution, it consists in the management of locations and stock levels, based on the actual consumption of products on the sales floor, including flow management, from production sites to installation in store shelves is obviously managed by the supplier.

VMI can reduce Bullwhip Effect by 50\% (Disney and Towell, 2003). It is part of a confiding approach by the distributor who, in exchange for providing information on its sales and stocks, avoids the constraints of supply, and benefits from an increased service rate. The supplier, on the other hand, benefits from a significant reduction in the uncertainty relating to the forecasting of final demand and, at the same time, a reduction in his safety 
stock. It also benefits from a drop in logistics costs, delivery times, transport costs, and an increase in the service rate. On the other hand, the CPFR represents the most successful form of supply chain management. It reflects a situation where members of the supply chain exchange information and jointly manage the important processes of their supply chain, including sales forecasting. Like VMI, collaborative forecasting has proven to be successful in MCS practice. In theory, collaborative forecasting can reduce supply chain costs by an average of around 20\% (Aviv, 2001).

\subsection{The impact of EDI on the Bullwhip effect}

It is proven that the use of EDI significantly reduces information times, thus it should significantly reduce the Bullwhip effect, it should also lead to a reduction in related costs at all levels of the supply chain. When it comes to the transmission of information, EDI saves businesses considerable amounts of time and money. The variable cost savings derived from the fact that the documents exchanged are no longer recorded manually are estimated at 3.5 $15 \%$ of the value of the product (Chip, 1993). Procter and Gamble have estimated that their order processing cost ranges from US \$ 35- US \$ 75 per invoice due to manual intervention (Lee et al., 1997a), which is why companies often accumulate batches of command before issuing an order, thus generating one of the possible causes of the bullwhip effect (Lee et al., 1997a, b). Therefore, the use of EDI does not only benefit businesses by reducing order processing costs; the frequent replenishment of material requirements in small batches reduces distortions in the request for information, with a subsequent reduction in the boost effect and the excessive costs it generates. The ordering policy adopted by managers at different stages of the supply chain is frequently based on the average of the expected level of demand for each period of time and the expected range of variation. The objective of this policy is to ensure that there is sufficient stock to cover the situations of variations in demand during the period; logically, the longer the delay, the greater the multiplier effect of changes in predicted variability. This leads to greater amplification and fluctuations in the actual orders placed, which clearly intensifies the bullwhip effect. Therefore, any significant reduction in delays in the transfer of information through the EDI interface will provide benefits through the reduction in both the size and variability of orders placed, yet against the blow bullwhip effect. In addition, there will be a reduction in the harmful effect generated by the lack of feedback and the underestimation of deadlines (Sterman, 1989).

Another factor to be taken into consideration is that the amplifying effect extending along the supply chain tends to result in a level of production of finished products greatly exceeding the actual demand. This distortion obviously results in excess inventory throughout the chain. These unnecessary 
costs could be reduced by implementing measures such as EDI to counteract the bullwhip effect, reduce the excess material flowing along the supply chain, thereby reducing transport costs.

EDI also ensures the rapid transmission and sharing of fair and reliable information at the different levels of the supply chain, thus making it possible to counter another cause of the boost effect (Lee et al., 1997). The greater stability in orders placed with the plant will lead to more stable production levels. This will allow for more efficient planning of production, with a decrease in the need for costly corrections and therefore a reduction in costs in this direction. EDI affects and is affected by several environmental variables at the same time. It is therefore difficult to distinguish between the effects produced by these variables and those resulting specifically from the use of EDI compared to traditional systems. One of the obstacles to the adoption of EDI is, precisely, the difficulty of quantifying its cost and benefits (Benjamin et al., 1990; Pfeiffer, 1992; Emmelhainz, 5 1993). Another commonly cited barrier is the lack of public interest due to the lack of perception of the true benefits of EDI (Walton and Lewis, 1995).

To significantly reduce the bullwhip effect, EDI must be installed throughout the supply chain. One solution to convince business leaders at all stages of the chain of the potential benefits of this system would be to demonstrate how the supply chain works in a representative market where the only difference between two successive experiences is the use, or no, from EDI. It also seems that it will be necessary to prove that the possible reductions in costs and the advantages available for each level of the chain justify the cost and the efforts required to modify the existing methods by implementing EDI at each specific stage. . A number of studies show that many companies are forced by their suppliers or customers to adopt EDI without having a clear vision of the benefits it can generate (Mackay and Malcolm, 1996; Chen and Williams, 1998).

\section{Research methodology and results \\ 4.1. Research Methodology}

The approach of semi-structured interviews was adopted to confirm or reject the hypothesis of our research: the use of EDI at the various levels of the automotive supply chain will result in a considerable reduction of the bullwhip effect at the level of inventory, inventory management costs. We chose to interview various players in the automotive industry upstream and downstream (several levels of the automotive supply chain: automobile manufacturer, assembly plant, rank 1, rank 2 suppliers, exclusive distributor, subcontractor, branch, dealers ...). 


\begin{tabular}{|l|l|}
\hline \multicolumn{1}{|c|}{ Contacted Companies } & \multicolumn{1}{c|}{ People Resource } \\
\hline 2 assembly and bodywork factories & $\begin{array}{l}\text { Industrial Information Systems Project } \\
\text { Manager } \\
\text { Deputy Head of Technical Department } \\
\text { Supplier Relations Manager }\end{array}$ \\
\hline 1 exclusive importer & Logistics manager \\
\hline 1 wiring subcontractor & IT manager and technician \\
\hline 3 OEMs (tier 1 suppliers) & $\begin{array}{l}\text { Logistics managers } \\
\text { Customer Relations Manager }\end{array}$ \\
\hline 1 supplier rank 2 & Customer Relations Manager \\
\hline 1 Indian brand branch & Sales manager \\
\hline $\begin{array}{c}3 \text { dealers in Agadir with different products: } \\
- \text { High-end cars }\end{array}$ & $\begin{array}{l}\text { Sales manager } \\
\text { technical Manager } \\
\text { - Grench brand cars }\end{array}$ \\
$\begin{array}{l}\text { Director } \\
\text { Korkshop and Japanese cars }\end{array}$ & \\
\hline
\end{tabular}

For each company, semi-structured interviews lasting approximately 30 minutes with engineers, senior and middle managers in the fields of production, information systems and logistics were carried out and analyzed. These were followed by telephone conversations and emails providing additional information.

\subsection{Discussion of the results}

The following table presents the general summary of the interviews carried out with the various actors of the automotive industry in Morocco:

\begin{tabular}{|l|l|l|}
\hline \multicolumn{1}{|c|}{ EDI usage } & \multicolumn{1}{|c|}{ EDI users } & \multicolumn{1}{c|}{ No EDI Users } \\
\hline Activities & $\begin{array}{l}\text { Assembly plants } \\
\text { Exclusive car importer } \\
\text { Tier 1 suppliers } \\
\text { Tier 2 supplier } \\
\text { Dealer }\end{array}$ & $\begin{array}{l}\text { Branch } \\
\text { Dealers } \\
\text { Subcontractor } \\
\text { After-sales and repair } \\
\text { workshop }\end{array}$ \\
\hline Size & Large business and SMEs & \multicolumn{1}{c|}{ SME } \\
\hline Information system & $\begin{array}{l}\text { Highly Developed, Standard } \\
\text { Integrated System: ERP }\end{array}$ & $\begin{array}{l}\text { Not very developed, } \\
\text { no ERP }\end{array}$ \\
\hline $\begin{array}{l}\text { Existence and frequency of } \\
\text { the demand amplification } \\
\text { problem }\end{array}$ & $\begin{array}{l}\text { Sometimes, the origin: a cause } \\
\text { and effect link between the } \\
\text { instability of forecast production } \\
\text { programs and the boost } \\
\text { (increasing amplifications) } \\
\text { phenomenon generated along } \\
\text { the upstream logistics chain. }\end{array}$ & $\begin{array}{l}\text { Yes } \\
\text { Frequently }\end{array}$ \\
\hline $\begin{array}{l}\text { How do they prevent and / } \\
\text { or reduce the bullwhip } \\
\text { effect }\end{array}$ & $\begin{array}{l}\text { With EDI used throughout the } \\
\text { automotive supply chain, a } \\
\text { significant reduction in bullwhip } \\
\text { is observed: }\end{array}$ & $\begin{array}{l}\text { It depends on the } \\
\text { situation }\end{array}$ \\
\hline
\end{tabular}




\begin{tabular}{|c|c|c|}
\hline & $\begin{array}{l}\text { - On stocks, } \\
\text { - Sue inventory } \\
\text { management costs, } \\
\text { - On the instability } \\
\text { which makes it } \\
\text { possible to reduce the } \\
\text { circle of uncertainty } \\
\text { This translates into a reduction } \\
\text { in the Bullwhip effect } \\
\text { throughout the supply chain }\end{array}$ & $\begin{array}{l}\text { They cope with the } \\
\text { means available } \\
\text { Fast reactivity }\end{array}$ \\
\hline Explanations & $\begin{array}{l}\text { International standard system } \\
\text { imposed by the main supplier to } \\
\text { facilitate exchanges and } \\
\text { improve responsiveness, } \\
\text { Fewer errors, reliability, speed } \\
\text { and security }\end{array}$ & $\begin{array}{l}\text { Limited technological } \\
\text { means, insufficient } \\
\text { human skills in IT and } \\
\text { logistics, reduced } \\
\text { volume of exchanges not } \\
\text { requiring an EDI tool, } \\
\text { satisfaction of traditional } \\
\text { means. }\end{array}$ \\
\hline
\end{tabular}

The semi-structured interviews allowed us to validate the hypothesis that the use of EDI at different levels of the automotive supply chain results in a substantial reduction in the boost in inventory and in the costs of managing the vehicles. stocks. The interviewees knowing the phenomenon studied explained to us that EDI ensures a considerable reduction of this problem between the various actors of the Suppy chain thanks to the systematic sharing of information and the fluidity of the information flows useful for the good functioning of the company. . Other interviewees expressed their total ignorance of the bullwhip effect and explained after understanding the phenomenon that their reaction varies depending on the situation, but in general rapid reactivity helps them to avoid problems similar to the bullwhip effect with exploitation of available means.

We have noticed that there is a real gap between manufacturers who are ahead of the curve in terms of maturity and the world of certain suppliers who find it a bit difficult to keep up with EDI. Sometimes a good exchange of fax, e-mail with updated and reliable information works just as well, if not better. To improve the level of agility of forecasts provided by manufacturers of Tier 1, 2 and 3 suppliers, managers need a certain pragmatism to help Tier 1 suppliers communicate with Tier 2 suppliers and so after.

In fact, upstream in the chain, large companies practice EDI in their relations with manufacturers and / or suppliers in France, Spain, India, 
Morocco, etc. For example, assembly plants have strongly encouraged their first-tier suppliers to communicate with them via EDI because of its inherent ability to counteract the boost and also facilitate just-in-time practices that are largely used by car manufacturers. Suppliers who cannot comply risk being removed from the manufacturer's supplier portfolio. A company's supplier relations manager testifies that EDI is the most efficient system for rendering JIT information and production and dramatically reducing the bullwhip effect. Downstream, distributors have expressed a need for tools that standardize trade and avoid waste of time, errors and waste, but only one dealer uses EDI technology, which has been imposed by the main supplier. Other dealers continue to use traditional exchange tools such as fax, telephone, e-mail. The need to use electronic means to track orders and spare parts is not very urgent for some.

If we take into account the opinions of some companies, they feel that they are compelled to use EDI without having any real belief about the benefits that will be derived from its implementation. These companies compare the benefits with the corresponding costs and effort involved in implementing this technology. Managers may be aware of the possible benefits that derive from the implementation of EDI which makes it easier to negotiate about the possible exchange through EDI between companies operating in different levels of the chain, so that acceptable and fair results can be enjoyed by all.

The study thus allowed us to validate the hypothesis that the use of EDI at the different levels of the automotive supply chain has a considerable influence on the substantial reduction of the boost and acts on stocks, on the costs of inventory management, and the instability that is typical of such systems. Clear improvements in the supply chain are noticeable, both as a whole and at each of its levels.

\section{Implications and perspectives}

Large companies operating in the automotive industry use EDI in their dealings with manufacturers in France, Spain, India, Morocco, etc. Among the main reasons mentioned was to prevent and counteract the bullwhip effect phenomenon by fully mastering the management of information flows between all levels of the supply chain. Also, the main customer of automotive components suppliers (assembly plant) strongly encouraged and even required its partners to communicate with it via EDI because of its inherent ability to avoid the boost effect and facilitate fair practices. -times which are widely used by car manufacturers. Suppliers who cannot comply risk becoming part of the Plant's supplier portfolio. The Director of Supplier Relations actually confirms that EDI is the best system for rendering JIT information and therefore reducing the bullwhip effect. Rapid response programs and the integration of new information technologies are, among others, other measures 
to counter the boost effect, they include the reduction of manufacturing cycle times (manufacturing process) ; by linking factories to customer demand (demand); more frequent and faster planning (planning and control); rationalization of acquisition and distribution (procurement) and new decision support systems (planning and control) to manage lead times reduction. The circle of uncertainty is a useful concept for improving the performance of supply chains through which every actor can make a profit. Uncertainties in the management of the control and manufacturing processes of a product can be greatly reduced through access to market data. To achieve a good degree of cooperation, partnership agreements can be a good way to achieve this. The optimum can only be achieved if strategies address uncertainty in both commodity and information pipelines.

\section{Conclusion}

The negative consequences of the bullwhip effect influence the profits made: too much stock, lost sales, poor customer service, insufficient quality and multiple disruptions to flow and organization. Since the real problem lies in the lack and the poor quality of information (both infrequent and not very credible) between production and consumption, the first step will be to make the business demand-driven (Lean Manufacturing and pull system ): She needs to have a vision of the entire supply chain and know what retailers are selling. Several solutions exist for this purpose:

- Apply Lean Manufacturing (flexibility and flexibility of production);

- Reduce confidence in forecasts;

- Increase the transparency of information by trusting the data coming directly from the final Customer;

- Transmit this information throughout the chain to avoid amplifying small variations.

- Place orders with the EDI or other computer system, which reduces order variations and, moreover, reduces administrative management costs.

- Avoid batch orders.

In summary, let us note that the Bullwhip effect is caused by the poor consideration by the logistics chain of the real demand of the final customer and by adopting a management oriented towards the satisfaction of the customer's demand, it is possible to eliminate most of the detrimental impacts of the Bullwhip effect.

Finally, it is necessary to merge EDI with new methods of logistics management, new means of inventory management and innovative production solutions because in the automobile, sources of supply are distant and cultures diverge, which has the effect is that other considerations begin to arise to 
ensure better efficiency in managing orders. The logistics of intercontinental JIT exchange systems across supply chains require that production be always on and EDI alone is not capable of solving these kinds of problems.

\section{References:}

1. Hau L. Lee. (2004). Information Distortion in a Supply Chain: The Bullwhip Effect. Management Science, Vol. 50, No. 12 Supplement, December 2004, pp. 1875-1886

2. Agrawal, S., Sengupta, R.N. et Shanker, K. (2009). Impact of information sharing and lead time on bullwhip effect and on-hand inventory, European Journal of Operational Research, $\mathrm{n}^{\circ}$ 192, pp.576593.

3. Jardini, B. Elkyal,M. Amri, M. (2015). The complexity of Electronic Data Interchange compliance for automotive supply chain. Industrial Engineering and Engineering Management (IEEM), 2015 IEEE International Conference on IEEE Xplore Digital library Year: 2015 Pages: 361 - 365, DOI: 10.1109/IEEM.2015.7385669 IEEE Conference Publications

4. Amblard, F. et Phan, D. (2006). Modélisation et simulation multiagents, Paris, Lavoisier.

5. Anthony, R.N. (1965). Planning and Control Systems: a framework for analysis, Harvard University Press.

6. Bailey, K. et Francis, M. (2008). Managing information flows for improved value chain performance, International Journal of Production Economics, $\mathrm{n}^{\circ} 111$, pp. 2-12.

7. Balan, S., Vratb, P. et Kumarc, P. (2009). Information distortion in a supply chain and its mitigation using soft computing approach, The International Journal of Management Science, ${ }^{\circ}$ 37, pp.282 - 299.

8. Bayraktar, E., Koh, L.S.C., Gunasekaran, A., Sari, K. et Tatoglu, E. (2008). The role of forecasting on bullwhip effect for E-SCM applications, International Journal of Production Economics, $\mathrm{n}^{\circ} 113$, pp.193-204.

9. Ben-Tal, A., Golany, B. et Shtern, S. (2009). Robust multi-echelon multi-period inventory control, European Journal of Operational Research, n 199, pp. 922-935.

10. Bolarín, F.C., Frutos, A.G. et Mcdonnell, L.R. (2009). The Influence of Lead Time Variability on Supply Chain Costs:Analysis of Its Impact on the Bullwhip Effect, The IUP Journal of Supply Chain Management, Vol. 6, n 3, pp. 16-26.

11. Cachon, G.P. et Fisher, M. (2000). Supply chain inventory management and the value of shared information, Management Science, Vol. 46, $\mathrm{n}^{\circ}$ 8, pp. 1032-1048. 
12. Cachon, G.P. et Lariviere, M.A. (2001). Contracting to assure supply : how to share demand forecasts in a supply chain, Management Science, Vol. 47, $\mathrm{n}^{\circ}$ 5, pp. 629-646.

13. Cachon, G.P., Randall, T. et Schmidt, G.M. (2007). In Search of the Bullwhip Effect, Manufacturing \& Service Operations Management, Vol. 9, $\mathrm{n}^{\circ}$ 4, pp. 457-479.

14. Jardini, B. Amri, M. Elkyal,M. (2015). L'EDI dans la logistique automobile au Maroc : entre exigences technologiques et pratiques classiques. Actes du Colloque Logistiqua 2015, EST, Safi, Université Cadi Ayyad, Marrakech, Maroc, Mai 2015

15. Jardini, B. Elkyal,M. Amri, M. (2016). Electronic Data Interchange In The Automotive Industry In Morocco : Toward The Optimization Of Logistical Information Flow. European Scientific Journal January 2016 edition vol.12, No.3 ISSN: 1857 - 7881 (Print) e -ISSN 18577431

16. Camisulis, C. et Giard, V. (2010). Détermination des stocks de sécurité dans une chaîne logistique-amont dédiée à une production de masse de produits fortement diversifiés, Journal Européen des Systèmes Automatisés, Vol. 44, pp. 975-1010.

17. Chan, F.T.S., Chung, S.H. et Wadhwa, S. (2004). A heuristic methodology for order distribution in a demand driven collaborative supply chain, International Journal of Production Research, Vol. 42, $\mathrm{n}^{\circ} 1$, pp. 1-19.

18. Chatfield, D.C., Kim, J.G. et Harriso, T.P. (2004). The Bullwhip Effect-Impact of Stochastic Lead Time, Information Quality, and Information Sharing: A Simulation Study, Production and Operations Management, Vol. 13, n 4, pp.340-353.

19. Chen, H., Chen, J. et Chen, Y. (2006). A coordination mechanism for a supply chain with demand information updating, International Journal of Production Economics, $\mathrm{n}^{\circ}$ 103, pp. 347-361.

20. Vallin, P. La logistique, modèles et méthodes du pilotage des flux, economica, 2003

21. Childerhouse, P. Hermiz, R. et al. Information flow in automotive supply chains - present industrial practice. Industrial Management \& Data Systems 103, 3 (2003), 137-149.

22. Butera, F. (1991). La métamorphose de l'organisation, du château au réseau, les éditions d'Organisation, 1991

23. Benedetti, C. Guillaume, J. (1992). Gestion des approvisionnements et des stocks, ERPI

24. Gossett, H.B. Parnell, C.R. (1993). Dundee builds on customer oriented strategy; textile world, 143, 10, october 1993, p. 72-76 
25. Waller, W.S. (1994) Discussion of motivating truthful subordinate reporting: an experimental investigation in a two-subordinate context. Contemporary Accounting Research.

26. Raymond, L. (1994). Echange de documents informatisés: une technologie stratégique pour les PME, Economique, vol. 18, no. 5, janvier 1994, pp.46-48

27. Rassameethes, B. Kurokawa, S. et al. EDI performance in the automotive supply chain. International Journal of Technology Management, v20, 3 (2000), 287-303.

28. Agi, M. Ballot, E. Molet, H. (2014) 100\% connected Elservier bv. 2014

29. Foued, A. (2009). Les conditions stratégiques pour une meilleure allocation des ressources dans les techniques de l'information (TI) : cas de l'échange de données informatiques (EDI) dans le secteur des équipementiers de l'automobile en France. la revue des sciences de gestion. 2009

30. Nagati, N. Jobin, M.H. (2009). Collaboration entre les acteurs de la chaîne logistiques : conditions de succès. gestion HEC Montréal. 2009

31. Baglin, G. Bruel, O. Garreau, A. et al. (2007). Management industriel et logistique, concevoir et piloter la Supply Chain. 5ème édition, economica 2007 